\section{The water "shoesize" vs. footprint of bioenergy}

Gerbens-Leenes et al. (1) quantify water use of the most relevant global bioenergy crops except palm oil. This is a welcome addition to the existing literature, which often only focuses on "carbon footprints." Although carbon footprints have been shown to capture a large portion of overall environmental effects for many products and services, the agricultural sector needs additional consideration of other environmental indicators (2). In particular, land use and water consumption can be of substantial importance. Calculating a water footprint is therefore crucial for agriculture-based products.

As the carbon footprint elaboration has shown, a clear concept and definitions of terms are required for proper communication (3). While in carbon footprinting weighting between various greenhouse gases according to global warming potentials is needed, we think that a distinction between the various origins of water use is useful, because the resulting environmental impacts vary largely from region to region. For instance, $1 \mathrm{~L}$ of water consumed in the Colorado watershed does not compare to $1 \mathrm{~L}$ of water from the Mississippi, because water is much more scarce in the Colorado watershed. Therefore, an extension of the work performed by GerbensLeenes and colleagues seems necessary to us, to capture environmental relevance. To clarify our view, a water footprint scheme consistent to that of carbon footprinting in terms of the relevant features is presented in Table 1. It deviates, in part, from the water footprint as presented by GerbensLeenes et al. and shows that a further discussion of the concept is necessary.

In the proposed scheme, only consumptive blue water is considered, because it describes the additional loss of available water resource in a watershed. This is in agreement with the concept presented by Gerbens-Leenes et al., because they quantify irrigation water as the consumptive fraction, and not the total use. "Green water" consumption

\begin{tabular}{lcccc} 
Crop & $\begin{array}{c}\text { Total water } \\
\text { (from ref. 1), } \\
\mathrm{m}^{3} / \mathrm{GJ}\end{array}$ & $\begin{array}{c}\text { Blue water } \\
\text { (from } \\
\text { ref. 1), } \\
\mathrm{m}^{3} / \mathrm{G} \text { J }\end{array}$ & $\begin{array}{c}\text { Water stress } \\
\text { index } \\
\text { (based on } \\
\text { ref. 4) }\end{array}$ & $\begin{array}{c}\text { Water footprint } \\
\text { (Colorado-m } \\
\text { equivalent) } \\
\mathrm{m}^{3} / \mathrm{GJ} \text { J }\end{array}$ \\
\hline $\begin{array}{l}\text { Ethanol } \\
\text { Sugar beet }\end{array}$ & 59 & 35 & 0.434 & 30 \\
$\begin{array}{l}\text { Potato } \\
\text { Sugar cane }\end{array}$ & 103 & 46 & 0.380 & 35 \\
Maize & 108 & 58 & 0.456 & 53 \\
Cassava & 110 & 43 & 0.287 & 25 \\
Barley & 125 & 18 & 0.087 & 3 \\
Rye & 171 & 89 & 0.320 & 57 \\
Paddy rice & 191 & 79 & 0.336 & 53 \\
Wheat & 211 & 123 & 0.490 & 69 \\
Sorghum & 419 & 182 & 0.488 & 120 \\
Biodiesel & & & & 157 \\
Soybean & 394 & 217 & 0.217 & 94 \\
Rapeseed & 409 & 245 & 0.683 & 335 \\
Jatropha & 574 & 335 & 0.251 & 169 \\
\hline
\end{tabular}

"Total water" and "blue water" values are taken from ref. 1. Blue water is then weighted by the crop average water stress index (WSI), resulting in the water footprint. The water footprint is here normalized over the reference WSI value of the Colorado watershed (WSI of 1.00) resulting in Colorado $\mathrm{m}^{3}$ equivalents.

of agricultural systems may be neglected, similar to biogenic $\mathrm{CO}_{2}$ emissions in carbon footprinting, if it is comparable to the green water demands of the natural vegetation at the specific site. However, we disagree on the water footprint definition, assuming that the water footprint should reflect the environmental impact. We perceive the reported definition of Gerbens-Leenes et al. rather as a water "shoesize" requiring a specific weight for becoming a footprint. Hence, we suggest a spatially varying water stress index (WSI) to weight the water consumption (shoesize), as a function of water scarcity (4). For illustration purposes, we calculated the stress-weighted footprints of biofuels according to ref. 4 based on the data presented by Gerbens-Leenes and colleagues. We normalized them with the WSI of the Colorado watershed resulting "Colorado- $\mathrm{m}^{3}$-equivalents" in analogy to $\mathrm{CO}_{2}$ equivalents (Table 2). The resulting volumes show some interesting and relevant alterations to the results of

Table 1. Suggestion of a water footprint scheme and comparison to the existing carbon footprint scheme

Described feature

Environmental concern

Flow perspective

Neglected flows

"Shoesize" (unweighted relevant flow)

Specific weighting

Footprint (weighted relevant flow)
Water footprint scheme

Carbon footprint scheme

\author{
Greenhouse gas emission (output) \\ Total carbon emission \\ Biogenic carbon emissions \\ Fossil carbon emissions (plus biogenic carbon \\ emissions from land transformation, e.g. \\ cut-down of rainforest) \\ Based on substance (global warming potential) \\ $\mathrm{CO}_{2}$ equivalent \\ (fossil carbon emission weighted with \\ substance-specific Global Warming Potential and \\ expressed in terms of reference substance)
}

*Green water is the water, which is available on-site (precipitation and soil moisture).

${ }^{\dagger} \mathrm{B}$ lue water is runoff water used for irrigation (groundwater or surface water). 
Gerbens-Leenes et al. (1). For instance, jatropha has a considerably lower footprint than rapeseed, maize is now favorable over sugar beet, and cassava has clearly the smallest water footprint. Such differences reflect the global distribution of biofuel production and the according water scarcities. They become even more pronounced if biofuels from specific regions are compared.

\section{Stephan Pfister ${ }^{1}$ and Stefanie Hellweg}

ETH Zurich, Institute of Environmental Engineering, 8093 Zurich, Switzerland
1. Gerbens-Leenes W, Hoekstra AY, van der Meer TH (2009) The water footprint of bioenergy. Proc Natl Acad Sci USA 106:10219-10223.

2. Weidema BP, Thrane M, Christensen P, Schmidt J, Lokke S (2008) Carbon footprint-A catalyst for life cycle assessment? J Ind Ecol 12:3-6.

3. Sinden G (2009) The contribution of PAS 2050 to the evolution of international greenhouse gas emission standards. Int J Life Cycle Assess 14:195-203.

4. Pfister S, Koehler A, Hellweg S (2009) Assessing the Environmental Impacts of Freshwater Consumption in LCA. Environ Sci Technol 43:4098-4104.

Author contributions: S.P. analyzed data; and S.P. and S.H. wrote the paper.

The authors declare no conflict of interest.

${ }^{1}$ To whom correspondence should be addressed. E-mail: pfister@ifu.baug.ethz.ch. 